\title{
A Rationale for the Limitation Period in Sales Law
}

\author{
Lando, Henrik
}

Document Version

Final published version

Publication date:

2007

License

CC BY-NC-ND

Citation for published version (APA):

Lando, H. (2007). A Rationale for the Limitation Period in Sales Law. Department of industrial Economics, Copenhagen Business School.

Link to publication in CBS Research Portal

\section{General rights}

Copyright and moral rights for the publications made accessible in the public portal are retained by the authors and/or other copyright owners and it is a condition of accessing publications that users recognise and abide by the legal requirements associated with these rights.

Take down policy

If you believe that this document breaches copyright please contact us (research.lib@cbs.dk) providing details, and we will remove access to the work immediately and investigate your claim. 


\title{
A Rationale for the Limitation Period in Sales Law*
}

\author{
Henrik Lando
}

May 28, 2007

\begin{abstract}
This article suggests a rationale for statutes of limitations in sales law, i.e. for the practice of cutting off buyers' remedies after the expiration of a limitation period. The rationale is based on the notion of wear and tear, which carries two implications: First, a good that breaks down after several periods of use is likely to be of nearly optimal quality, and in this case little is gained by allowing a claim. Second, the number of dysfunctions is likely to increase over time, which implies that the pool of potential claims, and in particular the pool of unjustified claims, is likely to increase over time. It will be shown theoretically that these implications can provide a rationale for cutting off claims. The rationale will be supported with empirical evidence stemming from a recent extension of the limitation period from one to two years in Denmark.
\end{abstract}

JEL: K12, K40

*I wish to thank law professor Peter Møgelvang-Hansen for cooperation on the survey study from which the data material of the present arcticle is drawn. Thanks also for research assistance to Bo Kristensen and Ole Schützsack. Errors are mine. 


\section{Introduction}

In the area of consumer sales law, statutes of limitations are criticized for lowering the incentive for producers of avoiding defects that occur after the expiration of the limitation period. Naturally, barring claims lowers administrative costs, but the question arises why older claims should be more administratively costly or less valuable in terms of deterrence than claims of more recent origin. One answer is that evidence deteriorates over time ${ }^{1}$, and that older claims are hence more costly and more likely to result in error, but in the context of sales the relevant evidence typically concerns the state of the good at the time of the dysfunction rather than at the time of purchase ${ }^{2}$. Another answer focuses on the fact that buyer's use the good with different intensity, and explains the limited duration of warranties as a response to buyer moral hazard ${ }^{3}$. However, as will be further explained below, buyer moral hazard is less important when the buyer bears the burden of proof, as she generally does within the rules of sales law, but generally does not do within the terms of a warranty agreement. Other answers have been provided, but none that applies well to sales law, and so the question in effect remains unanswered. This is unfortunate not only for policy making but also potentially for private contracting parties in search of a principle for determining the duration of the buyer's claim for remedies while putting the burden of proof concerning the nature of the defect on the buyer.

The present article suggests a rationale based on the obvious observation that most goods lose functionality over time, since it is not economically optimal (nor perhaps even possible) to secure the longevity of goods beyond some future point. Hence, the dysfunctions which are socially worth preventing will tend to become fewer in number over time, and each dysfunction will tend to become only marginally worthwhile preventing. Thus, the beneficial effect on incentives of allowing a claim is likely to fall over time, while there is no reason to believe the same about the administrative cost per claim, which may even increase as uncertainty about the validity of the claim increases over time. In conclusion, the ratio of the incentive benefit to the administrative cost is likely to fall over time, and, as will be argued further below, it may then be better to cut off claims entirely at

\footnotetext{
${ }^{1}$ This argument is made by Landes and Posner [9], as further described in the literature review below.

${ }^{2}$ In some cases, the reasonable expectations of the buyer need to be taken into account, and evidence of this kind may of course deteriorate.

${ }^{3}$ See e.g. Cooper and John[3], Dybvig and Lutz [4]. Emons [5] explains the limited duration of warranties in terms of adverse selection, see below.
} 
some point than to e.g. introduce time-increasing standards of proof or increasing administrative fees for raising claims.

The rationale can also be formulated as follows. It is well-known that the incentive for parties to litigate may be socially inoptimal even though the parties carry the costs of litigation themselves, see e.g. Shavell [14]. That is, under a rule of strict liability, which is in an approximate sense the rule of sales law, if the deterrent effect of litigation is small, litigation can be excessive. If the incentive to produce goods of sufficient quality induced by the buyer's access to remedies falls over time, and if it is not feasible to increase fees for raising claims over time, it may be optimal to bar claims from some point in time onwards, especially in the context of sales law where the incentive effect of claims is modified by the fact that producers and sellers often have the incentive to maintain a good reputation with customers.

The trade-off between incentives and administrative costs will be formalized below, and empirical data will be presented to demonstrate the real-world nature of the trade-off. The data indicate that retailers left out quality goods from their selection as a consequence of the legal change, and also indicate a rise in at the number of both justified and unjustified claims following the extension of the limitation period.

Two additional remarks: First, the optimal limitation period will be different for different goods, and if the legal rule can only stipulate one period, it must be determined as perhaps a weighted average of goods for which the limitation period plays a role. Moreover, for especially long-lived goods the seller is likely to offer a warranty that outlasts the average optimal average period, and these goods should then of course not enter into the average. Second, the administrative costs include the time spent by the buyer and the seller in verifying the nature of the dysfunction, in negotiating about the remedy, and in occasionally litigating the claim. Verification can obviously be costly as when it involves technical investigations $^{4}$, and so can time consuming and potentially unpleasant discussions at the shop level, often mentioned by retailers.

Section 2 analyzes the legal framework, and section 3 presents an overview of the literature bearing on limitation periods. Section 4 presents and analyzes a model in which the rationale for a limitation period arises from a trade-of between incentives and administrative costs. Section 5 takes up the point that only unwarranted clams arise in the equilibrium of the model. The section discusses how

\footnotetext{
${ }^{4}$ Such investigations are particularly likely to be undertaken when the parties differ in their beliefs about the origin of the dysfunction.
} 
the rationale extends to situations where warranted claims arise in equilibrium. Section 6 presents the empirical data, and section 7 provides final remarks.

\section{Legal Framework}

The legal framework to be addressed here concerns the extension of default and mandatory limitation periods, the remedies available to the buyer, rules concerning the burden of proof, and the definition of a defective (or non-performing) good. Readers not interested in the legal rules may skip this section; the model can be understood without the details presented below. However, as will become clear, the legal detail is in effect relevant for the determination of the optimal duration of the limitation period.

The law in most countries stipulates both a default limitation period which applies when the parties have not agreed otherwise, and a mandatory minimum limitation period (a shorter period is not allowed) that applies for consumer sales. The default limitation period varies widely between countries. For example, Finland has no default limitation period, which means that in the absence of a contractual agreement, the general limitation period of ten years applies, while in Denmark, the default period is two years for both sales to consumers and to businesses. The EU-directive 1999/44/EF, which was implemented in Denmark in 2002, required member states to adopt a minimum period of no less than two years for consumer sales.

In terms of remedies available to the buyer, the law distinguishes consumer contracts from business-to-business contracts. As part of the implementation of the EU-Directive, Danish consumer law now grants the consumer the choice between repair and replacement unless the cost of replacement is disproportionately high, in which case the seller can insist on repair ${ }^{5}$. Before the implementation of the directive, the choice belonged to the seller, which remains the case for business-to-business contracts. The seller has a right to perform, in the sense that he can insist on either repairing or replacing the good, before the consumer (or the business buyer - the law does not distinguish in this regard) can claim a reduction in price or cancel (terminate) the contract.

Two specific rules may provide independent reason for limiting the duration of claims $^{6}$ : First, when the type of good purchased has been technically improved,

\footnotetext{
${ }^{5}$ When the particular type of good is no longer being produced, e.g. because it has been replaced by improved versions, the buyer has a right to a good of similar quality to the one originally purchased. This rule is addressed in the final section of this article.

${ }^{6}$ I am grateful to Lars Quistgård Bay, chief legal advisor to the Danish Chamber of Commerce, for bringing my attention to these further considerations.
} 
sellers can be required to offer the new improved product to the buyer as a replacement (when the old type is no longer produced and repair is not an option). Second, when a good is replaced, the new limitation period starts from the point in time of the replacement, which sequentially may provide the buyer with a prolonged period of remedies. These rules are costly to sellers/producers and would in the absence of a limitation period at some point become inefficient ${ }^{7}$.

As part of the implementation of the EU directive, a presumption rule was enacted that transfers the burden of proof from the consumer to the seller for the first six months after sale. During this period, the dysfunction will presumptively be due to a defect (which implies that it was present at the time of purchase).

Finally, as will be important in the context of the model, the legal definition of a defective good recognizes that goods are neither supposed to last forever nor to be able to withstand all types of uses or external conditions. For example, it may not be considered a defect if a mobile phone breaks down after heavy use over several years, or if it breaks down due to exposure to abnormal temperatures. The legal rule lays down that a breakdown should only be considered non-performance when the dysfunction should not have been expected by a rational buyer (with regard also to the price of the product).

\section{The Literature}

The issue of the optimal extension of limitation periods in sales law seems not to have been addressed in the law and economics literature. However, as mentioned, a closely related economic literature explains why warranties are of limited duration, based on the idea that buyers' use of products is subject to moral hazard. The idea is that as time passes defects become increasingly more likely to be caused by wrong usage, and increasingly less likely to be caused by original defects, see e.g. Dybvig and Lutz [4], and Cooper and Ross [3]. Cutting off claims at some point will then provide the second-best combination of buyer and seller incentives. As mentioned, this theory cannot, however, be directly applied to limitation periods, since warranties typically expand the rights of consumers by transferring the burden of proof to the seller, whereas sales law allocates it to the buyer $^{8}$. When the buyer bears the burden of proof, the possibility of wrong usage as a (hidden) cause of the dysfunction cannot in itself justify limitation periods,

\footnotetext{
${ }^{7}$ Naturally, one might modify these rules, but this involves a trade-off, and it might be preferable to grant a high level of protection of the buyer for a short time rather than a lower level of protection for a longer period.

${ }^{8}$ with the exception of the first six months after purchase, for consumer sales, as noted above.
} 
since when wrong usage has caused the dysfunction, the claim is already cut off by the requirement that the buyer must prove the defect. The arguments raised by Cooper and Ross, and by Dybvig and Lutz rely on the seller carrying the burden of proof: the moral hazard of the buyer is considerably less important when the burden of proof is on the buyer.

Emons [5] explains the limited duration of warranties in terms of the producer's attempt to screen low-intensity users from high-intensity users. applies more to warranties than to a policy makers setting of a default limitation period. , which is the subject here.

An alternative explanation has been provided in the neighboring field of product liability law. Miceli [12] derives optimal statutes of limitations and statutes of repose ${ }^{9}$ based on a trade-off between incentives and administrative $\operatorname{costs}^{10}$. Longer duration increases incentives for care, but also increases the number of claims and hence administrative costs. But why should older claims be less likely to be worth their administrative cost in terms of accident prevention than younger ones? Miceli argues that a claim raised in period $t+\tau$ affects the injurer's incentives less than a claim raised at time $t$, because the injurer discounts future litigation costs when deciding the level of care. For this reason, the prospect of preventing a claim from arising at time $t+\tau$ is less important to the injurer compared with preventing a claim from arising at time $\tau^{11}$. Discounting future litigation costs seems, however, to be a more salient issue in product liability, where many years can pass from the time of the sale (or from the time of an accident) to when damages become apparent, as compared with sales law where limitation periods tend to be one, two or three years. Intuitively, the effect of discounting on future litigation costs seems of limited importance for sales ${ }^{12}$.

Landes and Posner [9] emphasize that evidence deteriorates over time, and that trials occurring long after the sale of the good are therefore both more costly in terms of evidence production and more likely to result in error, as compared to trials occurring shortly after the sale, when more can be remembered and more

\footnotetext{
${ }^{9}$ Statutes of repose run from when the good was sold while statutes of limitations (generally) run from the time the accident occurred. Time may pass from when the accident occurs to the filing of a claim, e.g. because the victim does not discover the damage immediately.

${ }^{10}$ See also and Baker and Miceli [1] for an empirical analysis.

${ }^{11}$ Note that the social costs of litigation should also be discounted back in time; Miceli's rationale holds when the incentive effect on incentives of the injurer's discounting of future litigation costs outweighs the discounting of total litigation costs.

${ }^{12}$ Miceli's result also seems to hinge (to some extent) on the assumption of the American rule for allocating litigation costs.
} 
evidence is available. When error is more likely, the costs of litigation are harder to justify by their effect on deterrence. This explanation can account for the ubiquitousness of limitation periods in law (since many kinds of evidence deteriorate over time), but it suffers from two drawbacks in the context of sales law. First, it must account for why for old claims the standard of proof cannot instead be raised, which would cut off dubious claims while allowing clearly warranted claims. As will be mentioned below, this drawback is shared to some extent with the rationale presented in this paper. Second, as mentioned, and more importantly, deteriorating evidence does not seem to play a dominant role in the context of sales, where the main issue to be resolved is whether the good has met reasonable expectations, which can often be answered without the use of historic evidence.

It has been suggested, e.g. by Martin [11], that cutting off claims allows businesses (and consumers) to 'close their books', i.e. to dispose of old files. Again, however, this concern does not seem very important in the area of sales contracts. Specific details about the product are typically not needed to assess a dysfunction, and the buyer must keep proof of purchase.

Finally, shifting risk from the seller to the buyer may be thought to justify limitation periods, but why the creditor (the buyer) bears the risk at lower cost needs to be explained. The seller may be a large firm while the buyer may be a consumer or a small firm averse to risk. It seems difficult to account for the widespread use of limitation periods in private contracts on the basis of riskallocation.

In the following section it is analyzed under which assumptions the rationale based on a trade-off between incentives and administrative costs can be maintained.

\section{The Model}

Within a two period model, the question to be analyzed is under which conditions it is worth cutting off the buyers' claims after the first period, i.e. under which conditions the administrative costs saved by cutting off claims after the first period outweigh the dilution of the sellers' incentives for producing goods of adequate quality.

To formulate the idea that a good may be subject to more or less strain, states of nature will be indexed by the strain they impose on the product; a higher state signifies greater strain. Thus, the state space will be the interval $\Theta=$ $[0, \infty]$ in both periods of the model, and the quality or endurance of the good will be indexed by the critical state (number) in the interval it can withstand; 
if the state (and hence the strain) is higher, the good will dysfunction. Denote the quality of producer $i$ by $q_{i}$ and the state in period 1 which the good can withstand by $\sigma q_{i}$, where $\sigma>0$, such that a level of quality $q_{i}$ can be expected to ensure functionality in the interval $\left[0, \sigma q_{i}\right]$ in period 1 . Wear and tear can then be introduced by assuming that the good can withstand only the state $\rho q_{i}$ in period 2 , where $\rho<\sigma$.

A judge will find the good defective if it is below some required quality level, $q^{r}$. The corresponding states which the good is expected to endure in the two respective periods are then $\theta_{1}^{r}=\sigma q^{r}$ and $\theta_{2}^{r}=\rho q^{r}$.

The individual seller $i$ selects a level of quality $q_{i}$ from the set $[0 ; \bar{q}]$, where for convenience and without loss of generality, an upper bound is set on quality. Then, if e.g. the product becomes dysfunctional in a state $\theta_{1}<\sigma q^{r}$ in the first period, the product is defective (for it should only become dysfunctional in higher states), and the buyer then has a claim on the seller, while if it becomes defective in a state $\theta_{1}>\sigma q^{r}$, the buyer does not have a claim on the seller, but must pay for the repair herself.

As is standard, buyers are assumed to know the average quality of goods (i.e. which states the goods can usually withstand), but are assumed to be unable to observe the quality of the product of any individual seller. In reality, the producer rather than the seller determines quality and the seller can abrogate claims on the producer; this (frequent) source of conflict will not be part of the analysis; the producer and the seller will for analytical simplicity be lumped together as the seller.

In the absence of liability for defective goods, an individual seller $i$ will have an incentive to save on costs by free-riding on the quality delivered by the other sellers. Naturally, if all sellers do so, the price will fall in the market as buyers anticipate or learn about the level of quality provided. An equilibrium arises when no seller has an incentive to lower or raise the quality even though an individual seller can lower quality at no reduction in price.

It will be assumed for simplicity that the strain to which the good is likely to be exposed is the same in both periods; the density function of states (strains) in both periods will be $h(\theta)$. To avoid uninteresting mathematical complications, it will be assumed that $h$ is bounded above.

The product will be repaired in period 1 if it becomes dysfunctional - the question is only who should pay for the repair- and for simplicity, it will then be assumed to be of the same durability in period two, and treated as if it had not been dysfunctional in period 1 . 
The cost of producing quality $q$ will be denoted $C(q)$, and the marginal cost $C^{\prime}(q)$ will be denoted $c(q)$. For simplicity and to secure interior solutions, it will be assumed that $c(0)=0, c(q) \rightarrow \infty$ as $q \rightarrow \bar{q}$, and that $c^{\prime}(q)>0$.

The state-space approach allows a simple way of modeling mistakes. When a good breaks down, the buyer may either mistake the strain imposed on the good or the required level of qualities $\theta_{1}^{r}$ and $\theta_{2}^{r}$. Thus, when a good breaks down, the buyer compares her estimate of the state with her estimate of $\theta^{r}$, and if she believes $\theta^{r}$ is higher than $\theta$, i.e. that the good ought to withstand the perceived strain, she will think she has a warranted claim for remedies, and will then raise a claim $^{13}$. The probability that she mistakes the difference between the actual and the required state by $x$ will be denoted $f(x)$ with distribution function $F(x)$, both defined on the interval ] $0 ; \infty[$. When the state is $\theta$ and the required level of quality is $\theta^{r}$, the buyer will make a claim when her mistake is larger than $\left(\theta-\theta^{r}\right)$. Since the probability of a smaller mistake than $\left(\theta-\theta^{r}\right)$ is $F\left(\theta-\theta^{r}\right)$, the probability of a mistake equal to or larger than $\left(\theta-\theta^{r}\right)$ equals $1-F\left(\theta-\theta^{r}\right)$.

State verification (and communication) costs are incurred when the buyer states she has a warranted claim. Whether the statement by the buyer is true or false, it will be costly for the parties to verify the state of nature; the costs of state verification $^{14}$ will be $\tau_{s}$ and $\tau_{b}$ for the seller and the buyer, respectively. By incurring these costs, the parties will discover the true state; the repair will be paid by the buyer if the claim is unwarranted and by the seller if it is warranted.

For simplicity, the buyer will be assumed to raise a claim whenever she believes she has a warranted claim. In reality, a buyer will compare the cost of raising a claim with the potential savings from shifting the repair cost to the seller, but introducing this aspect would complicate the analysis without adding insight of direct relevance to the main points here ${ }^{15}$. What is needed for the present analysis is the assumption that some people will raise unwarranted claims despite the cost of so doing, and this seems likely under a range of plausible assumptions.

When the required standard is $\theta^{r}$, the likelihood of a unwarranted claim raised by the buyer then equals $\int_{\theta^{r}}^{\infty}\left(1-F\left(\theta-\theta^{r}\right) h(\theta) d \theta\right.$.

The equilibrium when claims are never cut off will now be compared with that where claims are cut off after the first period. It will then be argued that

\footnotetext{
${ }^{13}$ On the incentive to raise a claim, see below.

${ }^{14}$ This is Townsend's costly state-verification principle [16].

${ }^{15}$ See Miceli [12] and Hylton [8] for modeling that does take the incentives for filing a claim into account.
} 
the incentive loss vanishes when $\rho$ becomes small, while administration costs are unlikely to fall as much as the incentive effect.

\subsection{The Equilibrium When Claims Are Never Cut Off}

For $q_{i}$ to be an optimal choice of quality, it must not be in the interest of seller $i$ to unilaterally lower or raise the quality from that level. When the required quality level is $q^{r}$ and claims are allowed in both periods, the cost to the seller of delivering quality $q_{i} \leq q^{r}$, will be the following. First, the cost of producing quality $q_{i}$ will be $C\left(q_{i}\right)$. Second, in the intervals $\left[q_{i} \sigma ; q^{r} \sigma\right]$ and $\left[q_{i} \rho ; q^{r} \rho\right]$, the good will be dysfunctional and claims will be warranted. Verifying the validity of the claim will incur a cost to the seller as will the repair. Hence, the cost of warranted claims will be $\int_{q_{i} \sigma}^{q^{r} \sigma}\left(R+\tau_{s}\right) h(\theta) d \theta$ in period 1 , while it will be $\int_{q_{i} \rho}^{q^{r} \rho}\left(R+\tau_{s}\right) h(\theta) d \theta$ in period 2 . Third, in the states $] q^{r} \sigma ; \infty[$ and $] q^{r} \rho ; \infty[$, the buyer will raise a claim whenever she is sufficiently mistaken about the state, and this will impose a cost $\tau_{s}$ on the seller; the repair will be paid by the buyer since it will be discovered that (while the good was in effect dysfunctional) the dysfunction cannot be considered a defect. Hence, the repair cost does not enter as a cost to the seller in those states. Fourth, in the states $] q^{r} \sigma ; \infty$ [and $] q^{r} \rho ; \infty[$, the buyer will raise a claim whenever she is sufficiently mistaken about the state, and this will impose a cost $\tau_{s}$ on the seller. There will be no cost of repair to the seller, since it will be discovered that (while the good was in effect dysfunctional) the dysfunction cannot be ascribed to the good being defective. Hence, the cost of mistaken claims will be $\left.\int_{q^{r} \sigma}^{\infty} \tau_{s}\left(1-F\left(\theta-q^{r} \sigma\right)\right)\right) h(\theta) d \theta$ and $\left.\int_{q^{r} \rho}^{\infty} \tau_{s}\left(1-F\left(\theta-q^{r} \rho\right)\right)\right) h(\theta) d \theta$ in the respective periods. Thus, the total cost from producing a level of quality below par is:

$$
\begin{aligned}
& \left.(A): C\left(q_{i}\right)+\int_{q_{i} \sigma}^{q^{r} \sigma}\left(R+\tau_{s}\right) h(\theta) d \theta+\int_{q_{i} \rho}^{q^{r} \rho}\left(R+\tau_{s}\right) h(\theta) d \theta+\int_{q^{r} \sigma}^{\infty} \tau_{s}\left(1-F\left(\theta-q^{r} \sigma\right)\right)\right) h(\theta) d \theta \\
& \left.+\int_{q^{r} \rho}^{\infty} \tau_{s}\left(1-F\left(\theta-q^{r} \rho\right)\right)\right) h(\theta) d \theta
\end{aligned}
$$

On the other hand, when delivering $q_{i} \geq q^{r}$, the total cost to the seller becomes $(B): C\left(q_{i}\right)+\int_{q_{i} \sigma}^{\infty} \tau_{s}\left(1-F\left(\theta-q^{r} \sigma\right)\right) h(\theta) d \theta+\int_{q_{i} \rho}^{\infty} \tau_{s}\left(1-F\left(\theta-q^{r} \rho\right)\right) h(\theta) d \theta$

Raising the quality then only serves the purpose of preventing breakdowns that may be mistaken for defects.

The question is which $q_{i}$ minimizes total cost. It will now be shown that, 
subject to a sufficient but not necessary condition on the second order derivative ${ }^{16}$, any $q$ fulfilling:

$$
(C): \tau_{s}(1-F(0))<\frac{c(q)}{\sigma h(q \sigma)+\rho h(q \rho)}<R+\tau_{s}
$$

will be an optimal response if it is the legally required level of quality.

Proof: see Appendix A

To narrow down the set of equilibria, the legal system will be assumed to require the efficient level of quality. This is given as the solution to:

$$
(D): \frac{c(q)}{\sigma h(q \sigma)+\rho h(q \rho)}=R
$$

This equilibrium selection does not prejudice the analysis against allowing claims; if the judge were assumed to require an inefficient level of quality and this leads to a rationale for not allowing claims (undoing the inefficiency created by the judge), the result might be said to follow from the equilibrium selection. On the other hand, the equilibrium selection can be criticized for not allowing the judge to maximize social welfare by taking into account the administrative cost of handling claims. The judge may seek the social optimum by in essence cutting off claims that are not clearly worth their administrative cost. This possibility will be discussed in the final section below.

Denote the solution to $(D)$ by $q^{*}$. It will be assumed that $R>\tau_{s}(1-F(0))$, such that when $q^{*}$ is required it will be optimal for the seller to deliver that (and not a higher) level of quality. $q^{*}$ will then not only be the required level of quality, but also the actual level of quality delivered by each seller as well as the level of quality expected by the buyer.

\subsection{The Equilibrium When Claims Are Cut Off After One Period}

Denote the level of quality when claims are cut off by $q_{l}^{*}$, where the subscript $l$ stands for the existence of a limitation period. Following the logic presented above, $q_{l}^{*}$ is the solution to $\frac{c(q)}{\sigma h(q \sigma)}=R$.

Note that $q^{*}>q_{l}^{*}$, since $\rho h(q \rho)>0$ and $c^{\prime}(q)>0$.

\footnotetext{
${ }^{16}$ The second-order condition requires $c^{\prime}\left(q_{i}\right)-\sigma^{2}\left(R+\tau_{s}\right) h^{\prime}\left(q_{i} \sigma\right)-\rho^{2}\left(R+\tau_{s}\right) h^{\prime}\left(q_{i} \rho\right)$ to be positive. This will be fulfilled e.g. when $h$ is close to a uniform distribution (for then $h^{\prime}$ will be near zero), if $h$ is normally distributed and quality is at the right hand side of the normal distribution where the derivative $h^{\prime}$ is negative, and it will generally be fulfilled if $c^{\prime}(q)$ is high.
} 


\subsection{The Effect on Incentives of Cutting Off Claims}

It will now be shown that the incentive loss from cutting off claims after one period will diminish with the extent to which wear and tear sets in. The parameter $\rho$ expresses the extent of wear and tear, i.e. the extent to which goods naturally tend to become dysfunctional over time, and the result will be that as wear and tear becomes more important, i.e. as $\rho$ decreases, the incentive effect of cutting off claims diminishes. The incentive effect is given by the difference between $q^{*}$ and $q_{l}$, i.e. by the difference between $q^{*}$ given by $\frac{c\left(q^{*}\right)}{\sigma h\left(q^{*} \sigma\right)+\rho h\left(q^{*} \rho\right)}=R$ and $q_{l}$ given by $\frac{c\left(q_{l}\right)}{\sigma h\left(q_{l} \sigma\right)}=R$. Consider the limiting case where $\rho$ approaches zero. The important point is that the difference between $q^{*}$ and $q_{l}$ will then approach zero. This follows from the fact that $\rho h\left(q^{*} \rho\right)$ ) can be made arbitrarily small when $\rho$ converges to zero, given the assumption that $h$ is bounded above. Moreover, when $q^{*}$ approaches $q_{l}$, the loss in terms of allocative efficiency will also approach zero. This follows from a comparison of total costs when claims are cut off after one period with total costs when claims are cut off after two periods (i.e. never). The total costs when $q=q_{l}^{*}$ are $C\left(q_{l}^{*}\right)+\int_{q_{l}^{*} \sigma}^{\infty}\left(R h(\theta) d \theta+\int_{q_{l}^{*} \rho}^{\infty} R h(\theta) d \theta\right.$, while the total costs when $q=q^{*}$ are $C\left(q^{*}\right)+\int_{q^{*} \sigma}^{\infty}\left(R h(\theta) d \theta+\int_{q^{*} \rho}^{\infty} R h(\theta) d \theta\right.$. The difference between these two constitutes the allocative loss (disregarding administrative costs) of cutting off claims after one period. The allocative loss is

$$
C\left(q_{l}^{*}\right)-C\left(q^{*}\right)+\int_{q_{l}^{*} \sigma}^{q^{*} \sigma}\left(R h(\theta) d \theta+\int_{q_{l}^{*} \rho}^{q^{*} \rho} R h(\theta) d \theta\right.
$$

which clearly converges towards zero when $q_{l}^{*}$ converges towards $q^{*}$.

The intuition is straightforward. As a consequence of wear and tear, the number of states for which it is optimal to prevent dysfunction as compared with repairing the good when it becomes dysfunctional decreases over time. While it will remain optimal from the viewpoint of allocative efficiency to allow claims in the final period (since only dysfunctions worth preventing are considered defects), preventing dysfunctions that occur in the final period (and not before) will become increasingly costly and only marginally worthwhile ${ }^{17}$.

\footnotetext{
${ }^{17}$ Naturally, the point where this occurs will be different for different goods.
} 


\subsection{On the Efficiency of Cutting Off Claims After the First Period}

In reality, both warranted and unwarranted claims give rise to administrative costs whereas only unwarranted claims arise in the model. It will now be shown that if a fraction $\beta$ (however small) of mistakes leads to claims, there will be a rationale for cutting off claims at some point. The following proposition concerns the limit when $\rho$ converges to zero, but the same effects as will be shown to apply in the limit apply also outside the limit ${ }^{18}$.

Proposition: When $f(x)>0, h(\theta)$ is bounded above, and a positive fraction $\beta$ (however small) of buyers who mistakenly believe they hold a warranted claim raise their claim, then when $\rho$ is sufficiently small, i.e. when wear and tear is sufficiently important, the savings from cutting off claims in the second period exceed the loss due to the seller's diminished incentives for delivering quality.

Proof: When claims are allowed in both periods, and the fraction $\beta$ of buyers, who mistakenly believe they hold a warranted claim, raise a claim, total costs to both buyers and sellers become:

$$
\begin{aligned}
& (E): C\left(q^{*}\right)+\int_{q^{*} \sigma}^{\infty} R h(\theta) d \theta+\int_{q^{*} \rho}^{\infty} R h(\theta) d \theta+\int_{q^{*} \sigma}^{\infty}\left(\tau_{s}+\tau_{b}\right)\left(1-F\left(\theta-q^{*} \sigma\right)\right) h(\theta) d \theta \\
& +\beta \int_{q^{*} \rho}^{\infty}\left(\tau_{s}+\tau_{b}\right)\left(1-F\left(\theta-q^{*} \rho\right)\right) h(\theta) d \theta
\end{aligned}
$$

When claims are cut off after the first period, total costs are:

$$
C\left(q_{l}^{*}\right)+\int_{q_{l}^{*} \sigma}^{\infty} R h(\theta) d \theta+\int_{q_{l}^{*} \rho}^{\infty} R h(\theta) d \theta+\beta \int_{q_{l}^{*} \sigma}^{\infty}\left(\tau_{s}+\tau_{b}\right)\left(1-F\left(\theta-q_{l}^{*} \sigma\right)\right) h(\theta) d \theta
$$

Subtracting total costs when claims are cut off from total costs when claims are not cut off yields:

$$
\begin{aligned}
C\left(q_{l}^{*}\right)-C\left(q^{*}\right)+\int_{q_{l}^{*} \sigma}^{q^{*} \sigma}\left(R h(\theta) d \theta+\int_{q_{l}^{*} \rho}^{q^{*} \rho} R h(\theta) d \theta+\right. \\
\beta \int_{q_{l}^{*} \sigma}^{\infty}\left(\tau_{s}+\tau_{b}\right)\left(1-F\left(\theta-q_{l}^{*} \sigma\right)\right) h(\theta) d \theta- \\
\beta \int_{q^{*} \sigma}^{\infty}\left(\tau_{s}+\tau_{b}\right)\left(1-F\left(\theta-q^{*} \sigma\right)\right) h(\theta) d \theta-\beta \int_{q^{*} \rho}^{\infty}\left(\tau_{s}+\tau_{b}\right)\left(1-F\left(\theta-q^{*} \rho\right)\right) h(\theta) d \theta
\end{aligned}
$$

\footnotetext{
${ }^{18}$ It is clear that claims should not be allowed when $\rho=0$, since there are then no valid claims, only administrative costs due to invalid claims. However, this does not bring out the forces that determine the optimal cut off level before $\rho=0$.
} 
When $\rho$ is small, so is the incentive effect of disallowing claims as argued above. As $\rho$ converges to $0, q^{*}$ will converge towards $q_{l}$, and $\beta \int_{q_{l}^{*} \sigma}^{\infty}\left(\tau_{s}+\tau_{b}\right)\left(1-F\left(\theta-q_{l}^{*} \sigma\right)\right) h(\theta) d \theta$ will converge towards

$$
\beta \int_{q^{*} \sigma}^{\infty}\left(\tau_{s}+\tau_{b}\right)\left(1-F\left(\theta-q^{*} \sigma\right)\right) h(\theta) d \theta
$$

Hence, the net effect of disallowing claims in the second period is the saving of error costs in the second period: $\beta \int_{q^{*} \rho}^{\infty}\left(\tau_{s}+\tau_{b}\right)\left(1-F\left(\theta-q^{*} \rho\right)\right) h(\theta) d \theta$. As a central point, this cost will not fall to zero and may well increase when $q^{*} \rho$ falls. It cannot converge to zero as $\rho$ converges to zero, given the assumptions that $h(\theta)>0$ and $f(x)>0$. To verify, take some interval of length $\partial$ to the right of origo. This interval will occur with positive probability, $\pi$. On this interval, $\left(1-F\left(\theta-q^{*} \rho\right)\right)$ will fall as $\theta$ increases, since the probability of larger mistakes falls with the size of the mistake. Take the value of $\left(1-F\left(\theta-q^{*} \rho\right)\right)$ at the end point of the interval, $1-F\left(\partial-q^{*} \rho\right)$. This will be a positive number given that the probability of an even larger mistake will remain positive by the assumption that $f(x)>0$. Hence, the error cost $\beta \int_{q^{*} \rho}^{\infty}\left(\tau_{s}+\tau_{b}\right)\left(1-F\left(\theta-q^{*} \rho\right)\right) h(\theta) d \theta$ will in the limit not fall below $\beta\left(\tau_{s}+\tau_{b}\right) \pi\left(1-F\left(\partial-q^{*} \rho\right)\right)$, which are all strictly positive numbers. Since the cost of handling unwarranted claims is hence strictly positive, it will be advantageous to cut off claims when $\rho$ becomes sufficiently small, i.e. when the allocative loss becomes sufficiently small. QED.

The result presents the trade-off in an intuitive way. The number of states in which dysfunctions are defects tends to decrease over time, while the number of states in which dysfunctions are the natural consequence of wear and tear increases. Even if only a small fraction of the increasing number of naturally occurring dysfunctions are viewed by buyers as defects and lead to claims, the costs of unwarranted claims will at one point exceed the positive incentive effect of allowing claims.

The model departs from reality in one important respect that now needs to be addressed.

\section{On Warranted Claims in Equilibrium}

There were no warranted claims in the equilibrium of the model, whereas in reality, warranted claims arise for several reasons. One reason is that it may not 
be optimal for the producer to deliver adequate quality when not all buyers raise claims. Raising a claim is costly to the buyer and the cost may not always be worth the often uncertain outcome. When warranted claims arise for this reason, it is ambiguous whether it strengthens the rationale for cutting off claims. On the one hand, cutting off claims will reduce the producer incentive further which in itself is inefficient, but this loss of incentives may not be great, since the situation is one where the producer is already not effectively deterred by the prospect of claims. On the other hand, administrative costs may be incurred without a compensating effect on incentives. Consider for illustration the case where quality is either 0 or 1 , and where too few claims are raised for it to be worthwhile for the producer to produce quality 1 . Cutting off claims will under these assumptions save administrative costs (of those claims that are raised) without affecting quality.

Another reason for warranted claims to arise is that some claims will be deemed to be warranted by a judge although in fact they would not be in a world of perfect information. For example, the durability of a good may be probabilistic, and it may be too expensive for a producer to reduce to zero the probability of breakdown. Thus, if the good turns out to be sub-par, which need not be due to negligence on the part of the producer, the producer will still be liable for remedies. Also, the judge will find for the buyer when there is a preponderance of evidence in her favor, which implies that the judge will sometimes make a wrong determination ${ }^{19}$. In sum, some claims which are in fact unwarranted (or which would be considered unwarranted by an omniscient judge) will be judged warranted, and there will be an incentive for the buyer to raise such claims. Evidently, the rationale suggested above will be strengthened by the existence of such claims, since they are costly to administer but do not add to efficiency.

Attention is now directed at the empirical evidence. The question to be addressed is whether the effects postulated in the model can be found in the data.

\section{Empirical Part}

\subsection{The Evidence}

In 2003, as the effect of the new law began to show in its second year, a survey was conducted (see [10]) involving retailers of durable goods. Of 1,300 questionnaires sent out, about 300 responded and of these, 291 responses were useful. The sectors were: used cars, new cars, computers and standard software, women's and men's clothing, electric home appliances, furniture, radio and television, shoes,

\footnotetext{
${ }^{19}$ Finally, producers may make mistakes, of course.
} 
and telecommunication products. Also, we obtained statistics from the Organization of Wholesale Distributors of Consumer Electronics in Denmark (BFE), which showed the increase in the number of repairs and replacements within this sector as a consequence of the legal changes introduced in 2002.

The data concern the effect on retailers' quality selection of goods and the effect on the number of claims and overall administrative costs.

\subsection{Empirical Findings Concerning the Impact on Incentives}

Table 1 below reveals that the extension of the limitation period seems to have affected retailers' quality selection of goods. The survey question asked was:

Have you, on the basis of the parameter in question $5 \mathrm{a}$ or $5 \mathrm{~b}$, discontinued the sale of any goods which were resulting in too many complaints?

Table 1

$\begin{array}{cccccc}\text { Sectors } & \mathrm{I} & \mathrm{F} & \text { No } & \text { Do not know } & \text { answers } \\ \text { All sectors } & 14.2 \% & 29.1 \% & 53.8 \% & 2.9 \% & 275 \\ \text { Used cars } & 22.7 \% & 36.4 \% & 31.8 \% & 9.1 \% & 22 \\ \text { Cars } & 11.5 \% & 19.2 \% & 69.2 \% & .0 \% & 26 \\ \text { Computers and software } & 18.8 \% & 39.1 \% & 39.1 \% & 3.1 \% & 64 \\ \text { Household appliances } & 18.2 \% & 18.2 \% & 59.1 \% & 4.5 \% & 22 \\ \text { Furniture } & 16.1 \% & 19.4 \% & 64.5 \% & .0 \% & 31 \\ \text { Radio and television } & 12.5 \% & 28.1 \% & 59.3 \% & 3.1 \% & 32 \\ \text { Clothing } & 6.3 \% & 28.1 \% & 72.7 \% & 6.3 \% & 32 \\ \text { Shoes } & 10.0 \% & 30.0 \% & 60.0 \% & .0 \% & 30 \\ \text { Telecommunication } & 6.3 \% & 31.3 \% & 62.5 \% & .0 \% & 16\end{array}$

I: Yes, it has indeed affected our range of products

$\mathrm{F}$ : Yes, but only in very few cases

Question 5a referred to in the question concerned whether customers bring claims more frequently than before whereas question $5 \mathrm{~b}$ concerned the extension of the limitation period.

Thus, in the aggregate, $14 \%$ of the respondents answered that it had in fact influenced their selection while $29 \%$ had made changes but only in a few cases. The remaining $54 \%$ of the sellers had made no changes. This indicates that although many are unaffected, seller behavior has been affected in the direction one would expect, and to a non-negligible extent. One other caveat should be mentioned. 
Although the question explicitly refers to the effect of the increase in claims, there is a possibility that the respondents fail to distinguish this from the effect of the presumption rule. Note for example that selection has been more heavily affected for used cars than for new cars which might well have to do with the presumption rule. However, it is hard to imagine the presumption rule plays a very significant role for televisions or radios, where a dysfunction shortly after purchase indicates an original defect (unless the item has been dropped in which case there will often be damage to suggest this). Yet, selection has been significantly affected also for television and radios, suggesting that the extended limitation period has indeed played an important role $^{20}$.

\subsection{Empirical Findings Concerning Administrative Costs}

\subsubsection{The Increase in the Number of Claims}

The survey question asked was: Do your customers make more claims now than before the change of law? The possible answers were: a) Much more frequently, b) A little more frequently, c) No change, d) Do not know.

The answers are shown in Table 2:

Table 2

$\begin{array}{cccccc}\text { Sectors } & \text { M.m.f } & \text { L.m.f } & \text { No change } & \text { Do not know } & \text { answers } \\ \text { All sectors } & 6.2 \% & 23.4 \% & 67.0 \% & 3.4 \% & 291 \\ \text { Used cars } & 9.1 \% & 31.8 \% & 50.0 \% & 9.1 \% & 22 \\ \text { Cars } & .0 \% & 37.9 \% & 62.1 \% & .0 \% & 29 \\ \text { Computers and software } & 3.1 \% & 16.9 \% & 76.9 \% & 3.1 \% & 65 \\ \text { Household appliances } & 4.3 \% & 17.4 \% & 78.3 \% & .0 \% & 23 \\ \text { Furniture } & 12.5 \% & 28.1 \% & 53.1 \% & 6.3 \% & 32 \\ \text { Radio and television } & 5.3 \% & 15.8 \% & 71.1 \% & 7.9 \% & 38 \\ \text { Clothing } & .0 \% & 24.2 \% & 72.7 \% & 3.0 \% & 33 \\ \text { Shoes } & 9.4 \% & 25.0 \% & 65.6 \% & .0 \% & 32 \\ \text { Telecommunication } & 23.5 \% & 23.5 \% & 52.9 \% & .0 \% & 17\end{array}$

M.m.f: Much more frequently

L.m.f: A little more frequently

\footnotetext{
${ }^{20}$ It should be added that some retailers may also been affected by consumers' increased right to demand a replacement. Survey responses revealed that there was a marked increase in the number of replacements, although many retailers simply disregarded the law in this regard (see Møgelvang-Hansen and Lando (2006)).
} 
Note that the presumption rule may again have caused the increase in claims; however, data for Consumer Electronics presented below indicate that the extension of the limitation did cause a substantial increase in claims in this sector, which indicates that the increase shown in Table 2 was in large part due to the new limitation period.

Apart from the survey data, the Organization of Wholesale Distributors of Consumer Electronics in Denmark (BFE) provided data showing the increase in the number of repairs and replacements as a consequence of the new deadline. The data covered audio-visual products such as DVD's, videos, disc-men, videocameras, and radio and television, and is graphically depicted in Møgelvang-Hansen and Lando (2006). For present purposes, the overall conclusion is that for this industry, the extension of the limitation period resulted in a $20 \%$ to $30 \%$ increase in the number of warranted claims for repair and replacement. As the radio and television sector was about average in Table 2 above, this suggests that the average increase in the sectors under investigation was in the neighborhood of $20 \%$.

\subsubsection{The Increase in the Number of Unwarranted Claims}

The survey also contained the following question:

Question: Has the number of unwarranted claims increased after the change of $\mathrm{law}^{21}$ ?

$\begin{array}{lllllll} & \text { L. Inc. } & \text { S. inc. } & \text { No change } & \text { Fall } & \text { Do not know } & \text { answers } \\ \text { All sectors } & 7.7 \% & 28.6 \% & 56.8 \% & .0 \% & 7.0 \% & 287 \\ \text { Used Cars } & 19.0 \% & 38.1 \% & 33.3 \% & .0 \% & 9.5 \% & 21 \\ \text { Cars } & .0 \% & 46.4 \% & 50.0 \% & .0 \% & 3.6 \% & 28 \\ \text { Computers/software } & 4.6 \% & 20.0 \% & 67.7 \% & .0 \% & 7.7 \% & 65 \\ \text { Household appliances } & 4.3 \% & 17.4 \% & 73.9 \% & .0 \% & 4.3 \% & 23 \\ \text { Furniture } & 9.4 \% & 25.0 \% & 50.0 \% & .0 \% & 15.6 \% & 32 \\ \text { Radio and TV } & 5.3 \% & 23.7 \% & 60.5 \% & .0 \% & 10.5 \% & 38 \\ \text { Clothing } & .0 \% & 25.0 \% & 68.8 \% & .0 \% & 6.3 \% & 32 \\ \text { Shoes } & 16.1 \% & 38.7 \% & 45.2 \% & .0 \% & .0 \% & 31 \\ \text { Telecommunication } & 23.5 \% & 41.2 \% & 35.3 \% & .0 \% & .0 \% & 17\end{array}$

L. Inc: Large increase

\footnotetext{
${ }^{21}$ Again, it should be noted that the law has shifted the burden of proof for the first six months which may perhaps affect the results.
} 


\section{S.inc: Small increase}

Again, there are significant differences between the different industries, reflecting nearly the same pattern as for the increase in claims. Overall, it appears that the increase in the number of unwarranted claims was somewhat larger than the increase in claims: On average, $29.6 \%$ respond that there has been either a large or a small increase in the number of claims while more than $36 \%$ respond that there has been either a large or small increase in the number of unwarranted claims. This is at least indicative of a significant increase in unwarranted claims, at least as perceived by retailers, consistent with the suggested rationale.

One caveat, however, must be mentioned. Part of the increase in the number of unwarranted claims as perceived by retailers ${ }^{22}$ may have been due to the presumption rule, which for the first six months puts the burden of proof on the seller. While claims raised under the presumption rule may have been legally warranted, retailers may have considered them unwarranted.

Still, the evidence is consistent with a significant increase in the number of unwarranted claims due to the extension of the limitation period.

\section{Final Remarks}

This section discusses the issue of buyer moral hazard, whether standards of proof or definitions of a defective good could be time-variant, and how the existence of warranties and contractually determined limitation periods should be taken into account when setting the legal default rule.

On the issue of buyer moral hazard, the model can be reinterpreted to take into account the fact that buyers use goods with different intensity. In the model, the state $\theta$ expresses the state of nature, but it could also express the intensity of use of a given type of buyer. The density function $h(\theta)$ would then express the distribution of types, and the quality of the good would determine a critical intensity of use that the good would be able to withstand in period 1 and 2 . In this framework, it is natural to assume that the court can neither observe the intensity of use nor the quality of the good (although both would sometimes be detectable by the court). Presumptions then become critical: if the good should not break down except under extreme use, the court would find for the buyer while the court would require some concrete proof of a defect if the presumption

\footnotetext{
${ }^{22}$ Our impression was that the retailers were generally trustworthy in their answers to our survey questions. For example, many reported that the new law had not affected their costs. But of course their answers are subjective.
} 
is in favor of the seller. The logic of the rationale suggested in the present article would translate into this setting as follows. As time passes after purchase, the presumption shifts in favor of the seller; at some point, while there may be buyers with justified claims, their number will be small, and so the incentive benefit of allowing their claim may be less than the administrative cost of verifying whether claims fall in this category.

As noted above, it may be argued that cutting off claims is not the only way to lower the number of claims raised. One might instead require a higher standard of proof or give a right to remedies only when the good is very significantly below adequate quality. Within the logic of the model, the buyer would then be discouraged from bringing a claim, unless it has clear merit. Indeed, nothing in the model provides reason to believe that an all-or-nothing solution is preferable to a more graduated approach that lowers the buyer's right over time. However, communicating to retailers or consumers time-varying standards of proof or timevarying required levels of quality would seem a difficult task in practice, and there would be uncertainty about when a dysfunction is clearly a defect ${ }^{23}$. Hence, the cost of administering the rule, of verifying whether claims belong in this category, may well from some point onward outweigh the incentive benefit of allowing a limited number of clearly justified claims.

How the legal regulation interacts with market forces such as warranties has not been touched upon in this article. Naturally, to the extent that goods that are supposed to last for many years are covered by warranties of longer duration (although, as noted by Emons the duration of warranties tends to be shorter than the life-time of the product), the optimal default rule, which then regulate goods of shorter expected lifetimes, will as mentioned also be shorter. More interestingly, one may wonder how the legally stipulated limitation periods, mainly the minimum period which applies to consumer sales, interacts with the signaling role $^{24}$ of warranties ${ }^{25}$. This is left for future research.

Appendix A:

\footnotetext{
${ }^{23}$ Time varying fees for bringing claims also seems a remote possibility in practice for similar reasons.

${ }^{24}$ First analyzed by Spence [15] and Grossman [7].

${ }^{25}$ In the Danish context, warranties are restricted by a regulation by the Consumer 'Ombudsmand', who has barred warranties of shorter duration than the mandatory limitation period. Thereby, the extension of the limitation period led to a decrease in the number of warranties. However, insurance policies similar to warranties have in some branches substituted for warranties.
} 
This appendix will prove that when $\frac{c\left(q^{r}\right)}{\left(\sigma h\left(q^{r} \sigma\right)+\rho h\left(q^{r} \rho\right)\right)}$ lies in the interval $\left[\tau_{s}(1-F(0)), R+\tau_{s}\right]$, and the derivative of $\frac{c(q)}{(\sigma h(q \sigma)+\rho h(q \rho))}$ is positive, i.e. when

$$
c^{\prime}\left(q_{i}\right)-\sigma^{2}\left(R+\tau_{s}\right) h^{\prime}\left(q_{i} \sigma\right)-\rho^{2}\left(R+\tau_{s}\right) h^{\prime}\left(q_{i} \rho\right)
$$

is positive, then $q^{r}$ is an optimal choice for the seller given that it is the required level of quality.

Note first that the derivative of total cost with respect to $q_{i}$ when $q_{i}$ is below $q^{r}$ is

$$
c\left(q_{i}\right)-\sigma\left(R+\tau_{s}\right) h\left(q_{i} \sigma\right)-\rho\left(R+\tau_{s}\right) h\left(q_{i} \rho\right)
$$

This will be negative when $q_{i}<q^{r}$ given that $\frac{c\left(q^{r}\right)}{\left(\sigma h\left(q^{r} \sigma\right)+\rho h\left(q^{r} \rho\right)\right)}<R+\tau_{s}$, and given that the derivative of $\frac{c(q)}{(\sigma h(q \sigma)+\rho h(q \rho))}$ is positive (for then $\frac{c(q)}{(\sigma h(q \sigma)+\rho h(q \rho))}$ will decrease when $q$ decreases, thus keeping below $R+\tau_{s}$ ). When the derivative of total cost is negative, increasing quality will be worthwhile when $q_{i}<q^{r}$. Hence, $q^{r}$ dominates any $q_{i}$ below it.

The right-hand derivative with respect to $q_{i}$ at $q^{r}$ equals $c\left(q^{r}\right)-\tau_{s}(1-F(0))\left(h\left(q^{r} \sigma\right) \sigma+\right.$ $\left.\rho h\left(q^{r} \rho\right)\right)$ as administrative costs due to mistakes are eliminated by an increase in quality in a small interval to the right of the equilibrium state. If $\tau_{s}(1-F(0))<$ $\frac{c\left(q^{r}\right)}{\left(\sigma h\left(q^{r} \sigma\right)+\rho h\left(q^{r} \rho\right)\right)}$, this will also hold for $q>q^{r}$ when the derivative of $\frac{c(q)}{\sigma h(q \sigma)+\rho h(q \rho)}$ is positive. When it holds, it is preferable to lower $q_{i}$ when $q_{i}>q^{r}$, hence $q^{r}$ is optimal.

\section{References}

[1] Baker, M. \& Miceli, T. (2000) Statutes of Limitations for Accident Cases: Theory and Evidence. Research in Law and Economics, 19, 47-67

[2] Cooter. R. \& Ulen, T. (2000). Law and Economics, New York: AddisonWesley-Longman.

[3] Cooper, R and Ross, T.W.(1985): Product Warranties and Double Moral Hazard; Rand Journal of Economics 16, 149-61.

[4] Dybvig, Philip H.; Lutz, Nancy A: Warranties, Durability, and Maintenance: Two-Sided Moral Hazard in a Continuous-Time Model, Review of Economic Studies, July 1993, v. 60, iss. 3, pp. 575-97. 
[5] Emond, Winand (1989): On the Limitation of Warranty Duration. Journal of Industrial Economics, v.37, iss. 3, 287-301.

[6] Epstein, R. (1986). Past and Future: the Temporal Dimension in the Law of Property. Washington Univ. Law Quarterly, 64, 667-722.

[7] Grossman, Sanford (1981): The Informational Role of Warranties and Private Disclosure of Quality, Journal of Law and Economics, 24, 461-83

[8] Hylton, K. (1990). The Influence of Litigation Costs on Deterrence under Strict Liability and under Negligence; International Review of Law and Economics, 10, 161-171.

[9] Landes, W. \& Posner, R. (1987). The Economic Structure of Tort Law, Cambridge, MA: Harvard Univ. Press.

[10] Lando, Henrik and Møgelvang-Hansen, Peter: New Rules for Consumer Purchases, An Empirical Investigation, see http://ir.lib.cbs.dk/download/ISBN/8791759056.pdf.

[11] Martin, M. (1982). A Statute of Repose for Product Liability Claims; Fordham Law Review, 50, 745-780.

[12] Miceli, Thomas: Deterrence, Litigation Costs, and the Statute of limitations for Tort Suits. International Review of Law and Economics, September 2000, v. 20, iss. 3, 383-94.

[13] Shavell, Steven: The Economic Analysis if Accident Law, Harvard University Press, 1987.

[14] Shavell, Steven (1982): The Social versus the Private Incentive to Bring Suit, Journal of Legal Studies, vol 11, n. 2, p. 333-339.

[15] Spence, Michael (1977): Consumer Misconceptions, Product Failure and Producer Liability, Review of Economic Studies, 44, 561-77.

[16] Townsend, Robert M., 1979. Optimal contracts and competitive markets with costly state verification, Journal of Economic Theory, Elsevier, vol. 21(2), pages 265-293. 